Lepr Rev (1992) 63, Supplement, 106s-113s

\title{
The role of health systems research in leprosy control
}

\author{
INDRA PATHMANATHAN
}

\section{Multidrug therapy and leprosy control}

The development of multidrug therapy (MDT) has provided the technology that could reduce leprosy to the level where it will no longer be a public health problem. However, although this technology is available, there are many problems in effectively applying it for the benefit of all leprosy patients.

At present only $55 \%$ of registered cases are on MDT and there is considerable variation in MDT coverage in different countries. Several issues have to be addressed in order to strengthen leprosy control programmes (Table 1).

A review of progress in MDT shows that in most countries:

some policies are not appropriate;

some aspects of many programmes are inadequate or unsuitable and the implementation is less effective than desired.

Changes are needed that enable all patients to be detected early and receive adequate MDT. These changes include the development of appropriate policies, the design of suitable programmes and the effective implementation of activities at the operational levels.

In order to be effective when making such changes, there is a need for detailed and accurate information to support decision making. However, such information is often lacking, inadequate or unreliable. As a result, decision making is often based on assumptions and unjustified opinions, and can result in inappropriate choices and decisions, which and discovered too late. The undesirable consequences are then usually corrected through a system of trial and error, without any factual assessment being made of the causes.

The various levels of decision making in the health system are well described in the WHO publication 'Managerial process for National Health Development' (1981). The policy and planning level determines the priorities, policies, broad objectives and strategies for control and involves politicians and higher level managers in the health and health-related services. The programme management level involves programme managers at midlevel, e.g. state, regional, district levels, NGOs, etc, and determines the activities, distribution of resources, etc. The technical and operational level determines the day-to-day activities, sets targets and monitors achievement relative to these targets. This level includes managers and supervisors at district level, clinical level, health teams, etc. 
Table 1. Multidrug therapy coverage: September, 1990

\begin{tabular}{lcc}
\hline & $\begin{array}{c}\text { No. of registered } \\
\text { cases } \times 1000\end{array}$ & \% on MDT \\
\hline African & 483 & $18 \cdot 4$ \\
American & 302 & $23 \cdot 7$ \\
E. Mediterranean & 100 & $38 \cdot 7$ \\
S.E. Asia & 2,693 & $66 \cdot 2$ \\
W. Pacific & 153 & $63 \cdot 4$ \\
European & 7 & $49 \cdot 7$ \\
\hline All & 3,738 & $55 \cdot 1$ \\
\hline
\end{tabular}

In addition to these managerial levels within the health and health-related services, it should also be remembered that decision making also involves families, community groups, etc.

\section{INFORMATION FOR DECISION MAKING}

Decision making at the policy level, programme management level and operational level each deals with different aspects of the major issues that are involved in implementing MDT for leprosy control. Appropriate information is needed for each level of decision making. As was stressed in the editorial published in Leprosy Review in 1989 entitled 'Priorities in Leprosy Control', research to provide suitable and accurate information for decision making in programme management should receive as much attention as research to provide information, for example, on immunological aspects of leprosy. Some examples of the types of information needed at the different levels of management are given in Table 2.

Currently the existing health information systems (HIS) routinely generate a great deal of data but much of this is not analysed and interpreted to provide meaningful information for managers to use in decision making. Health systems research (HSR) provides the means to analyse and interpret the masses of data routinely available from HIS to respond to the specific information needs of managers. Some of the information that is needed may not be routinely available and needs to be collected through specially designed studies. These are HSR studies.

\section{Purpose and uses of HSR}

HSR is the scientific method for acquiring information which can be used for rational decision making in health management. It is concerned with populations, organizational structures and the interaction between them. It provides information to identify health needs in specific contexts, to set priorities on an informed basis to facilitate the allocation of resources and foster a more equitable population-based approach that responds to the health needs of high risk and vulnerable groups. It also provides information to enable more effective application of available technology, to evaluate policies and programmes 
and suggests priorities for new research directions. HSR places health and disease in a larger context that takes account of social, economic and cultural factors.

Several illustrative examples of the types of information HSR studies have provided are given by the contributors to the WHO publication, 'Health Systems Research in Action' (1988).

In Botswana a study in a new agricultural development with large-scale migration provided information to determine appropriate stopping places for mobile dispensaries and developed a system for continued monitoring of health problems, particularly of migrants from other parts of the country who were at special risk in an unfamiliar environment. In Indonesia, a research project identified risk factors among pregnant women and developed a screening system which is used in 11 provinces to detect high-risk mothers and manage them at appropriate levels in the health system. In the USA, a number of studies influenced the debate and decisions on adaptation of the existing health systems by the consolidation of the health insurance system, financing of medical care for

Table 2. Examples of information needed for decision making in leprosy control

Type of decision making

Examples of some types of information needed which can be provided by health systems research

At the policy level

Determining the relative priority for MDT in the national expenditure on drugs

Integration of leprosy workers into general health services

At the programme management level Selection of appropriate strategies to improve case holding, e.g. what type of health educational approaches should be used?

Should accessibility be improved through mobile health teams or community workers or both?

Operational level

Improvement of accessibility of health services

Improvement of case detection
The relative mortality, morbidity, social and economic burden of the major health problems; and the relative effectiveness and acceptability of various drugs.

Educational, sex and age profile of leprosy workers; relative wage and service structures of leprosy workers in comparison with general health service workers; functional analysis of roles that can be reassigned and the type of training needed; attitudes of general health workers and leprosy workers towards integration, etc.

Attitudes and perceptions of various community groups in relation to leprosy and MDT; geographic patterns of the prevalence of leprosy and of defaulters from treatment; and the relative accessibility of health services; geographic distribution of health personnel in relation to the prevalence of leprosy; availability of local community resources that can supplement the health services, etc.

Attitudes of general health services personnel and the community towards leprosy and integrated lerposy services; knowledge of the community on availability of services; existing workload of peripheral staff mobile health teams, etc., and their potential to undertake management of MDT, etc.

Proportion of cases registered in advanced stages; knowledge and attitudes of community; knowledge and skills of relevant health staff; availability of adequate laboratory backup for peripheral health staff etc. 
the poor, the development of 'health maintenance organizations', and the adoption of medicare, all of which were intended to provide more equitable access to health care.

In Malaysia, a study on the low utilization of a mobile dispensary's services showed that the functions it originally served were now taken over by health subcentres and community nurse clinics that had been constructed subsequently and were now easily accessible to the 40 villages visited by the dispensary because communications had improved. This study led to a review of the mobile dispensary and clinic services in the area and a redeployment of resources.

In another study on the effectiveness of management of hypertensive patients in an outpatient clinic, it was found that for many patients the prescribed treatment regimens were inappropriate; and because of the rapid turnover of doctors, most were unaware of the criteria for management of hypertensives that had been established in that clinic. There was also no system to identify drop-outs, to recall defaulters, or to provide information and counselling for patients and their families. This study formed the basis for a series of planned interventions that improved the percentage of effectively managed hypertensive patients from $55 \%$ to $90 \%$.

Many of the problems addressed in the above examples are similar to the issues that affect the implementation of MDT in leprosy control. It is evident that HSR can provide valuable assistance in improving the effectiveness of leprosy control.

\section{HSR USED IN DECISION MAKING AT THE OPERATIONAL LEVEL}

The value of HSR in providing information for policy levels and for programme planning is rapidly gaining credence. However, at the midlevel management and operational levels there is little evidence that decision making is based on facts.

Research is often perceived as a grand venture that contributes to a major breakthrough in human knowledge or provides information for far-reaching changes in the health system. The examples quoted above show that HSR is equally useful in providing information for rational decision making at every level in the health system, including the operational level. Decision making at the operational level, e.g. the district medical officer of health, public health nurses, medical assistant, clinical supervisor etc., is affeced by fewer and less complex factors than it is at the higher levels. Therefore the type of information required is generally less complex, and the type of research that can provide such information is also simpler. Experience has shown that many such studies can be designed and conducted by health personnel at district and hospital level, provided they are appropriately trained and are supported and guided by experienced researchers who understand the concept and approaches of HSR.

\section{DO SIMPLE STUdiES' DONE AT HEALTH DISTRICT LEVEL DEMEAN THE LABEL} RESEARCH?

It is important to note that simple research should not mean poor quality. HSR studies done at the operational level can be easier to design and execute but will need to adhere to the same basic principles of research as other more sophisticated research.

When more and more health staff become competent in such research and use the findings it will be posible to ensure that the 'scientific method pervades all decisionmaking in health' and that data and information will be used as the 'rational basis of 


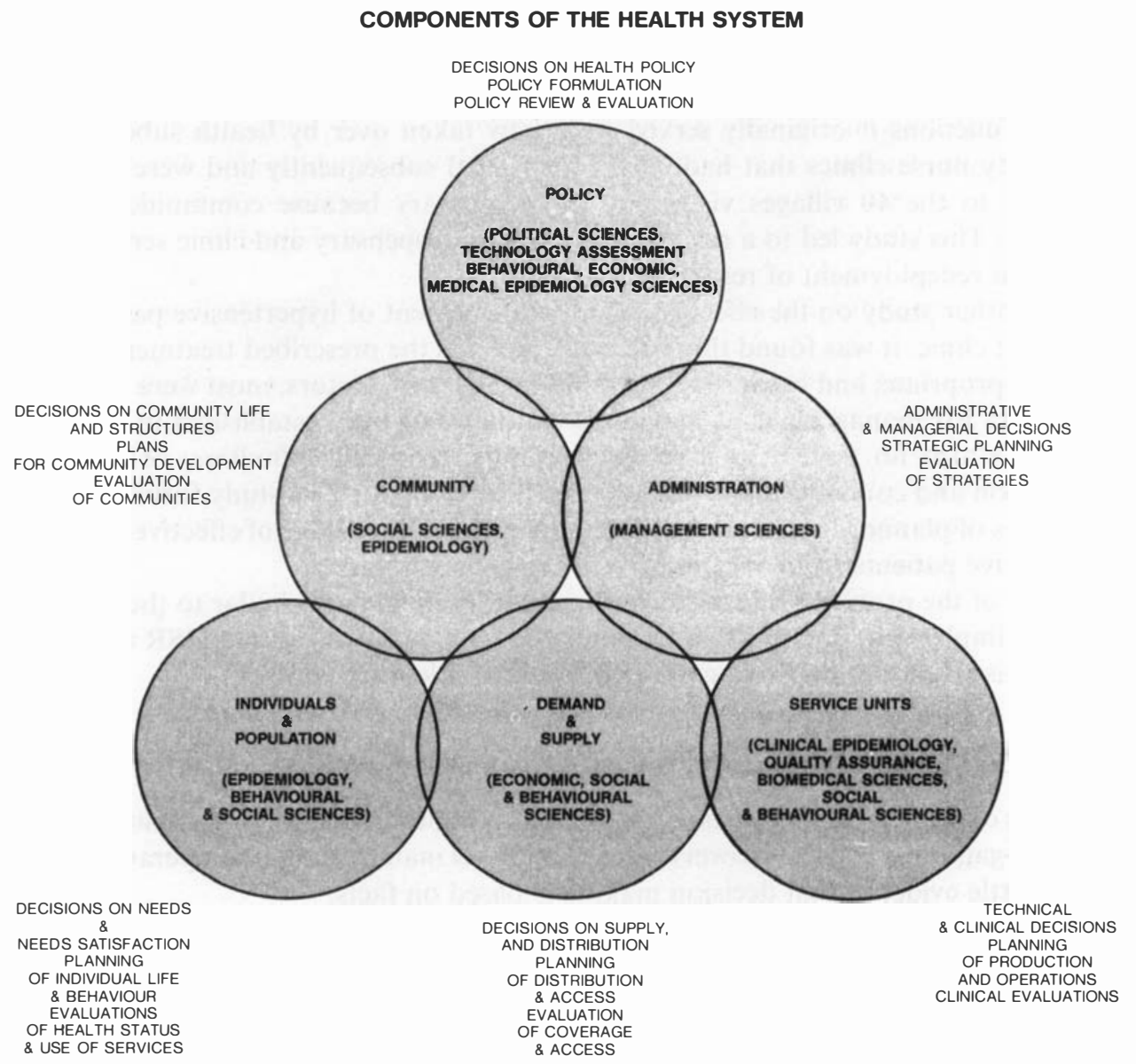

Figure 1. Components of the health system.

health care' as recommended by the Nobel Conference on Health Research and Development (1989).

\section{The nature of HSR}

\section{HSR IS MULTIDISCIPLINARY}

Since the purpose of HSR is to provide appropriate information for decision making in the health system, it is first useful to consider the health system itself and how various components of the health system interact and are inter-related, so that the design of HSR studies will focus on appropriate and relevant aspects of the problem that is being studied.

One way in which the different inter-related and interaction components of the health system may be depicted is illustrated in Figure 1. For example, a study aimed at reducing 'treatment failures' will need to obtain information on factors within the 'Service Units' (Figure 1) e.g. clinical decisions, health education, drug availability, etc.; 'Administra- 
tion', e.g. supervision, monitoring practices, etc; 'Supply and demand', e.g. clinic schedules, transport availability; 'Individuals and populations', e.g. attitudes and beliefs towards leprosy and MDT, economic pressures, etc.

In each of the components it is evident that decision making relates to a different set of concerns, and therefore the nature of the information that is needed is also different. In order to provide the appropriate type of information on issues in each component, the approaches and research techniques from different scientific disciplines, e.g. epidemiology, sociology, health economics, management, etc., are needed. Figure 1 illustrates some of the disciplines that are relevant to concerns in the various components of health system.

It is evident that HSR is multidisciplinary. In large and complex studies this may mean that researchers from different disciplines may need to co-operate, each contributing the relevant concepts and research techniques from their own disciplines in designing and executing the study. In simpler studies, it would be possible for researchers to be trained to apply the basic concepts and techniques from several disciplines, e.g. epidemiology and behavioural sciences, in their research projects.

\section{HSR IS PARTICIPATORY}

The participatory nature of HSR is one of its major characteristics. In order to ensure that the research is relevant and appropriate, everyone directly concerned with a particular health or health care problem should be involved in the research project(s). This could include policy-makers, health managers from the health services involved, health care providers and, if relevant, the community itself. This involvement is critical if the research activities are to make a difference:

- if decision makers are only involved after completion of the study, the report may just be shelved;

- if health staff are only involved in data collection and not in the development of the proposal or in data analysis, they may not be motivated to collect accurate data or carry out the recommendations;

- if the community is only requested to respond to a questionnaire, the recommendations from the study may not be acceptable;

- if professional researchers are not involved in the implementation of recommendations, they may have little concern for the feasibility of the recommendations.

\section{HSR MUST LEAD TO ACTION}

Since the purpose of HSR is to provide information for decision making in the health system it must be focused on priority problems and the results must be utilized in decision making.

There are several features that will enhance the likelihood that research findings will be utilized.

Studies should be scheduled so that the results are available when needed for key decisions, otherwise the research loses its usefulness, i.e. research must be timely.

Emphasis should be placed on comparatively simple, short-term research designs which probably will yield practical results relatively quickly. Simple but effective research 
designs are difficult to develop, but much more likely to yield useful results within the desired time.

The principle of cost-effectiveness is important in the selection of research projects. Research should focus, to a large extent, on low-cost studies that can be undertaken by health personnel at the management and services level in the course of their daily activities.

Results should be presented in formats most useful for administrators, decisionmakers and the community. Each report should include:

- a clear presentation of results with a summary of the major findings adapted to the interests of the target audience for the report;

- honest discussion of practical or methodological problems that could have affected the findings;

- alternative courses of action that could follow from the results and the advantages and drawbacks of each.

Evaluation of the research undertaken should not be by the number of papers published but by its ability to influence policy, improve services and ultimately lead to better health.

\section{HSR in leprosy control}

Until now the focus of research in leprosy control has been in furthering an understanding of the disease and its epidemiology; and in developing the technology to cure and prevent the disease. The stage has now been reached where it is necessary to focus research on ensuring that the benefits of the progress that has been achieved in terms of knowledge and technology are applied effectively for the benefit of all and not just some leprosy patients. It is HSR that provides the approaches that are needed for this purpose.

HSR is applicable and useful for providing information for the policy making, programme planning and operational levels of leprosy control programmes. It will be an extremely useful support for decision making in relation to implementation of MDT and is highly relevant with regard to current developments in leprosy control.

\section{Bibliography}

Hassouna WA. Health Systems Research in Egypt. Ibid.

Karolinska Institute. Nobel Conference No. 15. Health Research and Development. February 1990. SAREC Documentation Conference Report 1990: 1.

Loedin AA. Health Systems Research in Action. WHO, Geneva, 1988.

Lopez Bravo L. Global implementation of Multidrug Therapy in Report of the Regional Workshop Western Pacific Regional Office WHO Manila. 1990.

McDougall AC and Georgiev CD. Priorities in leprosy control. Editorial in Lepr Rev, 1989; 60: 1-7.

Meija Alfonso. Research for decision-making in health systems and manpower development in Columbia. In Health Systems Research in Action Who Geneva 1988.

Ownor-Omandi L. Improving health planning and management at district level in Botswana. Ibid.

Pathmanathan Indra. Health Systems Research Training Series Volume 4. Managing health systems research. International Development Research Centre (in press). 
Pathmanathan Indra. The nature and scope of health systems research. A paper prepared for a WHO Consultative Meeting to develop criteria for the appraisal of HSR Project Proposals. WHO, New Delhi, April, 1991.

Pathmanathan Indra and Kahlid bin Sahan Abdul. Health Systems Research a s a management tool. Ibid.

Revankar CR, Sorensen BH, Kielstrup RW and Multicentre Study Group. Delivery of MDT through blister calender packs in leprosy eradication programmes - a multicentre field study (Phase I). Lepr Rev, 1989; 60: 135-138.

Roemer Milton I. Health Systems Research and health systems strategies in the United States. Ibid.

Tedla Tadele and Lambo Eyitaya. Health Systems Research in Leprosy Control. A background paper prepared for a WHO meeting on Health Systems Research in Leprosy. Kana, Nigeria. Mac, 1990.

The Murlep Project. Multidisciplinary Research for improvement of leprosy control. Premises and Proposals. Royal Tropical Institute. Amsterdam December 1985.

Vorkevisser Corlien, Pathmanathan Indra and Brownlee Ann. Health Systems Research Training Series Volume 2, Designing and implementing health systems research projects. International Development Research Centre, (in press).

WHO. Research for the reorientation of national health systems. Report of a WHO Study Group. Geneva 1983 (Technical Report Series 694).

World Health Organization. Multidrug therapy for leprosy; an end of sight. Geneva. 1988.

World Health Organization. Report at the Regional Workshop on Leprosy Control. Regional Office for the Western Pacific. Manila. November 1990.

World Health Organization. Technical Discussion. Health Systems Research as part of the Managerial Process in support of the strategy for Health for All. Regional Committee for the Eastern Mediterranean. ThirtyFourth Session. EM/RC 34/Tech. Disc/June 1987.

World Health Organization. Updating of Regional Programme Profiles-Programme area 4.13.9 Leprosy. Geneva. January 1990. 